\title{
COMPARATIVE STUDY OF MECHANICAL PROPERTIES OF VARIOUS Ni-Ti BASED SHAPE MEMORY ALLOYS IN VIEW OF DENTAL AND MEDICAL APPLICATIONS
}

\author{
L. JORDAN, K. GOUBAA*,**, M. MASSE ${ }^{*, * *}$ and G. BOUQUET ${ }^{*, * *}$ \\ Faculté de Chirurgie Dentaire, 5, rue Garancière, F-75006 Paris, France \\ . Ecole Nationale Supérieure de Chimie de Paris, 11, rue Pierre et Marie Curie, F-75231 Paris cedex \\ 05, France \\ ${ }^{* *}$ Centre d'Etudes de Chimie Métallurgique, 15, rue Georges Urbain, F-94407 Vitry sur Seine cedex, \\ France
}

\begin{abstract}
NiTiCu and NiTiCo shape memory alloys are characterized in view of dental and medical applications. A binary alloy is taken as a reference. In this work we studied specially the efficient temperature ranges for such uses and the mechanical strength available from shape memory effect. Characteristic temperatures are determined by internal friction measurements while the mechanical behaviour is studied with the help of a "soft" torsion machine.
\end{abstract}

\section{INTRODUCTION}

Dental (1-4) and medical (5-12) applications of shape memory alloys are depending on various parameters such as transformation temperatures, transformation hysteresis, mechanical efficiency and biocompatibility. In this study we compare two families of ternary alloys, NiTiCu and NiTiCo, taking a binary NiTi alloy as a reference. The characterization of these materials is achieved with the help of internal friction measurements and mechanical tests realized on a "soft" torsion machine. The aim of this work is to determine the most appropriate alloy with regard to the considered applications where the human's body temperature $\left(37^{\circ} \mathrm{C}\right)$ plays a prominent part.

\section{EXPERIMENTAL RESULTS}

\subsection{Internal friction}

Internal friction measurements are performed on an automatized inverted pendulum (13) oscillating at the frequency of $1 \mathrm{~Hz}$. The specimens are $0,5 \times 7 \times 70 \mathrm{~nm}^{3}$ plates, preliminary annealed at $800^{\circ} \mathrm{C}$ under vacuum.

Internal friction spectra of $\mathrm{NiTi}$ alloys (Ni : $53 \mathrm{wt} \%$, $\mathrm{Ti}: 47 \mathrm{wt} \%$ ) obtained on heating and on cooling are reported in Fig. 1. A maximum of internal friction is associated with the martensitic transformation. In the same figure we have represented the relative torsion modulus evolution measured by the square of the frequency $F^{2}$. This quantity permits the setting of the temperatures $A_{s}, A_{f}, M_{s}, M_{f}$, by a working method illustrated in Fig. 1. In these conditions we find : $A_{S}=95^{\circ} \mathrm{C}, A_{f}=115^{\circ} \mathrm{C}, M_{S}=105^{\circ} \mathrm{C}, M_{f}=65^{\circ} \mathrm{C}$.

Such an alloy is unappropriate for medical or dental applications because of a transformation range far from $37^{\circ} \mathrm{C}$. Nevertheless some characteristics are determined such as a small transformation hysteresis $\left(\mathrm{A}_{\mathrm{S}}-\mathrm{Ms}\right.$ $=10^{\circ} \mathrm{C}$ ) and a narrow transformation range $\left(A_{f}-A_{s}=20^{\circ} \mathrm{C}, M_{f}-M_{S}=40^{\circ} \mathrm{C}\right)$.

The internal friction behaviour of NiTiCu alloys ( $\mathrm{Ni}: 50,7 \mathrm{wt} \%, \mathrm{Ti}: 44,3 \mathrm{wt} \%, \mathrm{Cu}: 5 \mathrm{wt} \%)$ is clearly different because we note three maxima on heating $\left(\mathrm{P}_{1}, \mathrm{P}_{2}, \mathrm{P}_{3}\right)$ and only two on cooling $\left(\mathrm{P}_{2}^{\prime}, \mathrm{P}_{3}^{\prime}\right)$. The maximum $P_{1}$ was associated with martensitic variants reorientation induced, on heating, by the interacting effects of temperature and shearing stresses inherent to the internal friction technique. $\mathrm{P}_{2}$ and $\mathrm{P}_{2}^{\prime}$ refer, respectively, to the inverse and direct martensitic transformation. Finally $P_{3}$ and $\mathrm{P}_{3}^{\prime}$ (Fig. 2) are related to 
the R-phase occurring on heating and on cooling. The utilization of the $F^{2}$ curves give $A_{S}=10^{\circ} \mathrm{C}, A_{f}=$ $45^{\circ} \mathrm{C}, \mathrm{M}_{\mathrm{s}}=30^{\circ} \mathrm{C}, \mathrm{M}_{\mathrm{f}}=-5^{\circ} \mathrm{C}$. We note immediately a transformation range, on heating, perfectly appropriate for medical or dental applications. In Fig. 2, we have reported different curves corresponding to various heating rate. These experimental conditions which imply heating cycles on the specimen do not lead to any shift of the characteristic transformation temperatures. It appears that the maximum $\mathrm{P}_{3}$ is more clearly described with a high heating rate $\left(25 \mathrm{Kh}^{-1}\right)$.

If we consider, now, the internal friction spectra of NiTiCo alloys, the curves are somewhat similar to those of NiTiCu (Fig. 3). On heating three $\mathrm{Q}^{-1}$ maxima are observed although $\mathrm{P}_{3}$ is difficult to distinguish. The wide maximum observed at low temperature $\left(-60^{\circ} \mathrm{C}\right)$ is not discussed here. On cooling $\mathrm{P}^{\prime} 3$ arises clearly. We said that $P_{3}$ and $P_{3}{ }_{3}$ are associated with the $R$-phase, therefore the modulus evolution $F^{2}$ denotes a strong dependence with regard to this $\mathrm{R}$-phase and for the determination of characteristic temperatures this phase will be considered as the martensitic transformation start. On such an assumption we find : $A_{S}=5^{\circ} \mathrm{C}, A_{f}=50^{\circ} \mathrm{C}, M_{S}=45^{\circ} \mathrm{C}, M_{f}=0^{\circ} \mathrm{C}$. At this stage a remark must be done concerning the effect of thermal cycling. We see that such a thermal treatment leads to a noticeable shift of the temperature position of the maximum $P^{\prime}$, i.e. the maximum associated with the martensitic transformation on cooling. This denotes a structural instability of the martensite and specially of martensitic variants configuration. Such a phenomenon was not observed so strongly in NiTi or NiTiCu alloys. Furthermore the effect of thermal cycling let unchanged the temperature position of the $\mathrm{Q}^{-1}$ maximum $\mathrm{P}^{\prime}{ }_{3}$ associated with the R-phase on cooling. This result is important because the R-phase producing a strong modulus effect, it implies that this transition can be considered as the true start of the martensitic transformation. We can compare the behaviour of NiTiCu and NiTiCo alloys by evaluating the quantities $\Delta T_{A}=A_{f}-A_{S}$ and $\Delta T_{M}=M_{S}-M_{f}$ :

$$
\begin{array}{ll}
\Delta \mathrm{T}_{\mathrm{A}}, \mathrm{NiTiCu}=35^{\circ} \mathrm{C} & \Delta \mathrm{T}_{\mathrm{A}}, \mathrm{NiTiCo}=45^{\circ} \mathrm{C} \\
\Delta \mathrm{T}_{\mathrm{M}}, \mathrm{NiTiCu}=40^{\circ} \mathrm{C} & \Delta \mathrm{T}_{\mathrm{M}}, \mathrm{NiTiCo}=45^{\circ} \mathrm{C} .
\end{array}
$$

This result means that the transformation kinetics is higher for $\mathrm{NiTiCu}$ alloys. We can also estimate the transformation hysteresis :

$$
\begin{array}{ll}
\left(\mathrm{M}_{s}-\mathrm{A}_{\mathrm{s}}\right) \mathrm{NiTiCu}=20^{\circ} \mathrm{C} & \left(\mathrm{M}_{\mathrm{s}}-\mathrm{A}_{\mathrm{s}}\right) \mathrm{NiTiCo}=40^{\circ} \mathrm{C} \\
\left(\mathrm{A}_{\mathrm{f}}-\mathrm{M}_{\mathrm{f}}\right) \mathrm{NiTiCu}=50^{\circ} \mathrm{C} & \left(\mathrm{A}_{\mathrm{f}}-\mathrm{M}_{\mathrm{f}}\right) \mathrm{NiTiCo}=50^{\circ} \mathrm{C}
\end{array}
$$

The transformation hysteresis is relatively narrow on heating for NiTiCu alloys, while on cooling the two materials exhibit a similar behaviour.

According to these results NiTiCu alloys appear as the most appropriate alloys for medical and dental applications if we take into account the transformation temperature range, the transformation hysteresis and the kinetics of the process. Now we have to compare the mechanical behaviour.

\subsection{Mechanical tests}

The mechanical tests were performed on a "soft" torsion machine (14). On such an apparatus we can follow the deformation evolution of a specimen as a function of an applied stress. In this case we draw a curve $\gamma=$ $\mathrm{f}(\tau)$ where $\gamma$ is a torsion angle (rd.mm-1) and $\tau$ is a shearing stress (MPa). An other possibility of this apparatus is to measure the deformation as a function of temperature, the specimen being submitted to a constant load.

\section{$\gamma=f(\tau)$ curves}

These experiments characterize the mechanical behaviour of the martensite because they are performed at low temperatures. On the curves reported in Fig. 4 we can determine the critical stress, $\tau_{c}$, at which the rubber-like behaviour starts and the corresponding deformation rate, the slope of the linear evolution where the reorientation of martensitic variants takes place and the length of the plateau. The results are the following :

\begin{tabular}{llll} 
& NiTi & NiTiCo & NiTiCu \\
\hline Elastic modulus (MPa) & & & \\
slope of the tangent at zero point & $245.10^{2}$ & 216.102 & $183.10^{2}$ \\
Elastic modulus on the plateau (MPa) & $13,27.10^{2}$ & $9,1.10^{2}$ & $5,64.10^{2}$
\end{tabular}

slope of the linear evolution 


\begin{tabular}{llll} 
& NiTi & NiTiCo & NiTiCu \\
\hline Critical stress for reorientation $\tau_{\mathrm{c}}(\mathrm{MPa})$ & 225 & 180 & 115 \\
Length of the plateau $($ rd.mm-1) & 17 & 31 & 40
\end{tabular}

These results allow to range the various alloys in a decreasing order relative to their mechanical strength : NiTi, NiTiCo, NiTiCu, but we must keep in mind that NiTi alloys are just a reference.

\section{$\gamma=f(T)$ curves}

This kind of curves brings informations similar to the ones given by $\mathrm{Q}^{-1}$ measurements about transformation temperatures. Nevertheless the important difference is that the tesis are performed under macroscopic stresses leading to structural modifications and shift in the transformation temperatures. Consequently in order to compare various materials, all the experiments must be realized under similar conditions of loading. The experiments are performed in the following way : the specimen is loaded at low temperature, i.e. in the martensitic phase; the chosen load is maintained during two cycles and at the end of the second one the specimen is unloaded and submitted to a third cycle. This last one permits an evaluation of a reverse memory effect. The results are reported in Fig. 5. In each case, the first cycle exhibits a maximum on heating, this maximum denotes the occurrence of martensitic variants reorientations (14), phenomenon which disappears during the second cycle. Because of this unstability our comparative study will concern only the second cycles. The curves in Fig. $5 \mathrm{a}$ and $5 \mathrm{~b}$ allows a comparison between the mechanical strength of NiTi and NiTiCo alloys. Indeed we note that, although the loading conditions are different (200 MPa for NiTi, $140 \mathrm{MPa}$ for NiTiCo) we observe similar corresponding deformation rates. This means that the NiTi alloys are more resistant than NiTiCo. In the same way, Fig. $5 \mathrm{c}$ and $5 \mathrm{~d}$ illustrate the specific behaviours of NiTiCo and NiTiCu alloys. NiTiCu, under a load more heavy ( $84 \mathrm{MPa}$ ), are less deformed than NiTiCo alloys (70 MPa). Consequently we find a classification somewhat different from the one obtained from the $\gamma=\mathrm{f}(\tau)$ curves, i.e. NiTi is the best alloy, then NiTiCu and finally NiTiCo. This mechanical behaviour of NiTiCo is confirmed when we observe the shapes of temperature cycles in Fig. 5 $\mathrm{c}$ and $5 \mathrm{~d}$ : we note cycles areas clearly lower for NiTiCu alloys. This implies a transformation hysteresis narrower and a tranformation kinetics faster, in these alloys. Thus these mechanical tests support the result obtained from internal friction experiments.

\section{DISCUSSION}

The experimental technics we use lead to a good characterization of our alloys with respect to the tranformation temperatures (in loaded or unloaded conditions) as well as to the mechanical behaviour. Internal friction results are difficult to interprete without considering the related modulus evolution. From such considerations we can determine remarkable points on the experimental curves, leading to the evaluation of the characteristic temperatures : $A_{S}, A_{f}, M_{S}, M_{f}$. These temperatures are specific of the considered material because they are measured under a shearing stress, associated with the $\mathrm{Q}^{-1}$ method, perfectly negligible. On the contrary the curves $\gamma=f\left(T^{\circ} \mathrm{C}\right)$, obtained under a constant load, bring informations similar to those deduced from $Q^{-1}$ spectra but the found values are depending on the amount of the chosen load.

When we compare the various results, NiTi alloys appear as having the best mechanical behaviour. However the transformation (direct or inverse) temperature range makes this material unappropriate for dental or medical applications, when the shape memory takes place under the only effect of the human's body temperature. Consequently our comparative study concerns the NiTiCo and NiTiCu alloys. From among these two families, NiTiCu alloys exhibit best properties for the applications considered previously : interesting transformation temperature range, mechanical efficiency, narrow hysteresis, fast transformation kinetics. However an other parameter has to be taken into account, is the biocompatibility. If this property seems good in the case of NiTi and NiTiCo alloys (15-17), on the contrary, for NiTiCu, the Cu content is undesirable. In these conditions NiTiCo alloys appear as the best material for dental or medical applications in spite of shape memory effects slightly lower than NiTiCu.

The main fundamental aspect of this study concerns the R-phase accompanied by modulus evolutions which make this phase efficient relative to the shape memory effect. Thermal cycling implies shift in the temperature of the martensitic transformation while the $R$-phase transition temperature is unmodified. Consequently care must be taken to precise $\mathbf{M}_{\mathbf{s}}$. When a R-phase stage occurs distinctly the temperature at which this transition starts must be considered as the " $\mathrm{M}_{\mathrm{s}}$ " temperature. 


\section{CONCLUSION}

Three families of shape memory alloys were studied in view of dental or medical applications : NiTi, $\mathrm{NiTiCu}, \mathrm{NiTiCo}$. Various parameters were taken into account : transformation temperature range, transformation hysteresis, transformation kinetics, mechanical efficiency. Internal friction experiments and torsion tests performed on a "soft" machine allowed us a comparative characterization of our alloys with respect to these parameters. Concerning the mechanical strength, NiTi alloys appear as the most interesting materials, but their transformation temperature range is unexploitable. From NiTiCo and $\mathrm{NiTiCu}$ alloys, these last ones exhibit the best mechanical behaviour in a well situated transformation temperature range, but their biocompatibility seems doubtful. Consequently NiTiCo alloys remain the most appropriate shape memory alloy for dental or medical applications.

\section{Acknowledgments}

The authors thank Miss Y. Correc for the mechanical tests on NiTiCo alloys and the "Fondation de France" for its support.

\section{References}

1) ANDREASEN G.F., Am. J., 78 (1980) 528

2) ANDREASEN G.F., BRADY P.R., Angle Ortho., 42 (1972) 172

3) ANDREASEN G.F., MONTANAGO L., KRELL D., Am. J. Oruhod., 82 (1982) 469

4) BOUQUET G., MASSE M., MISSIKA J.-M., PORTIER R., J. Biomat. Dent. 3 (1987) 207

5) CRAGG A., LUND G., RYSAVY J., CASTANEDA F., CASTANEDA-ZUNIGA W., AMPLATZ K., Radiology, 147 (1983) 261

6) KAMBIC H., SUTTON C., MURABAYASHI S., SUGITA Y., OKU T., HARASAKI H., SHIREY E., NOSE Y., Artif. Organs, 11 (1987) 343

7) OKU T., SUTTON C., KAMBIC H.E., HARASAKI H., NOSE Y., Trans. ASAIO, 34 (1988) 399

8) PALESTRANT A.M., PRINCE M., SIMON M., Radiology, 145 (1982) 351

9) SIMON M., KAPLOW R., SALZMAN E., FREIMAN D., Radiology 125 (1977) 89

10) SUGITA Y., SHIMOMITSU T., OKU T., MURABA YASHI S., KAMBIC H.E., Trans. ASAIO, 32 (1986) 30

11) KUO P.P.F., YANG PJ., ZHANG Y.F., YANG H.B., Orthopedics, 12 (1989) 111

12) JINFANG G., PING L., Proc. Int. Symp. on SMA (sept. 1986) 379 (China Acad. Publ.)

13) MASSE M., BESSENAY G., SIGLI C., GAFFET E., BOUQUET G., J. de Phys., C9 (1983) 347

14) GOUBAA K., ORLIONNET V., MASSE M., BOUQUET G., Scripta. Mct., 22 (1988) 1023

15) CUTRIGHT D.E., PEREZ B., JOHNSON R.M., COWAN S.M., Oral Surg., 35 (1973) 578

16) CASTLEMAN L.S., MO'TZKIN S.M., ALICANDRI F.R., BONAWIT V.L., J. Biomed. Mater. Res., 10 (1976) 695

17) VICENTINI B., RONDELLI G., CIGADA A., TURISINI G., Proc. Int. Symp. on SMA (1986) 447 (China Acad. Pub.).

Fig.1 : Internal friction spectra of Niti alloys

a) on heating

b) on cooling

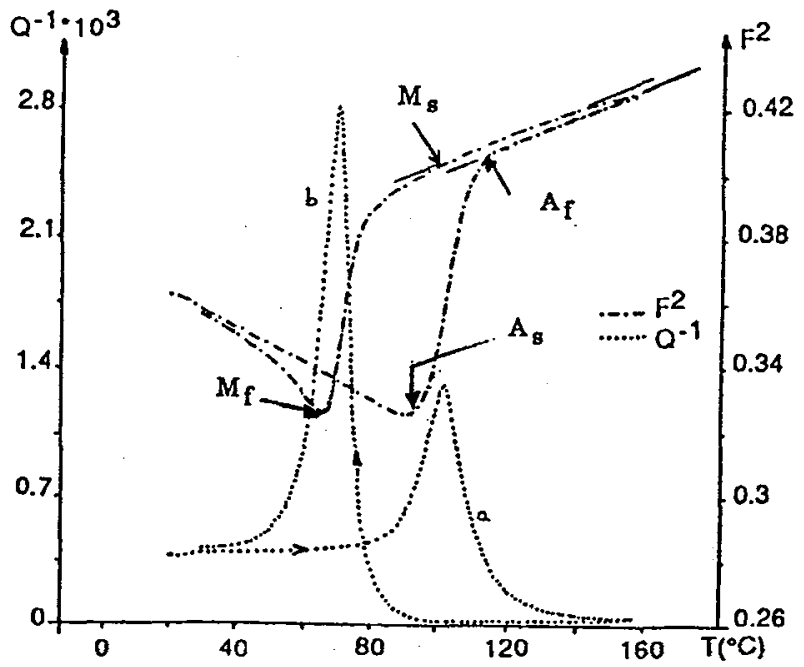



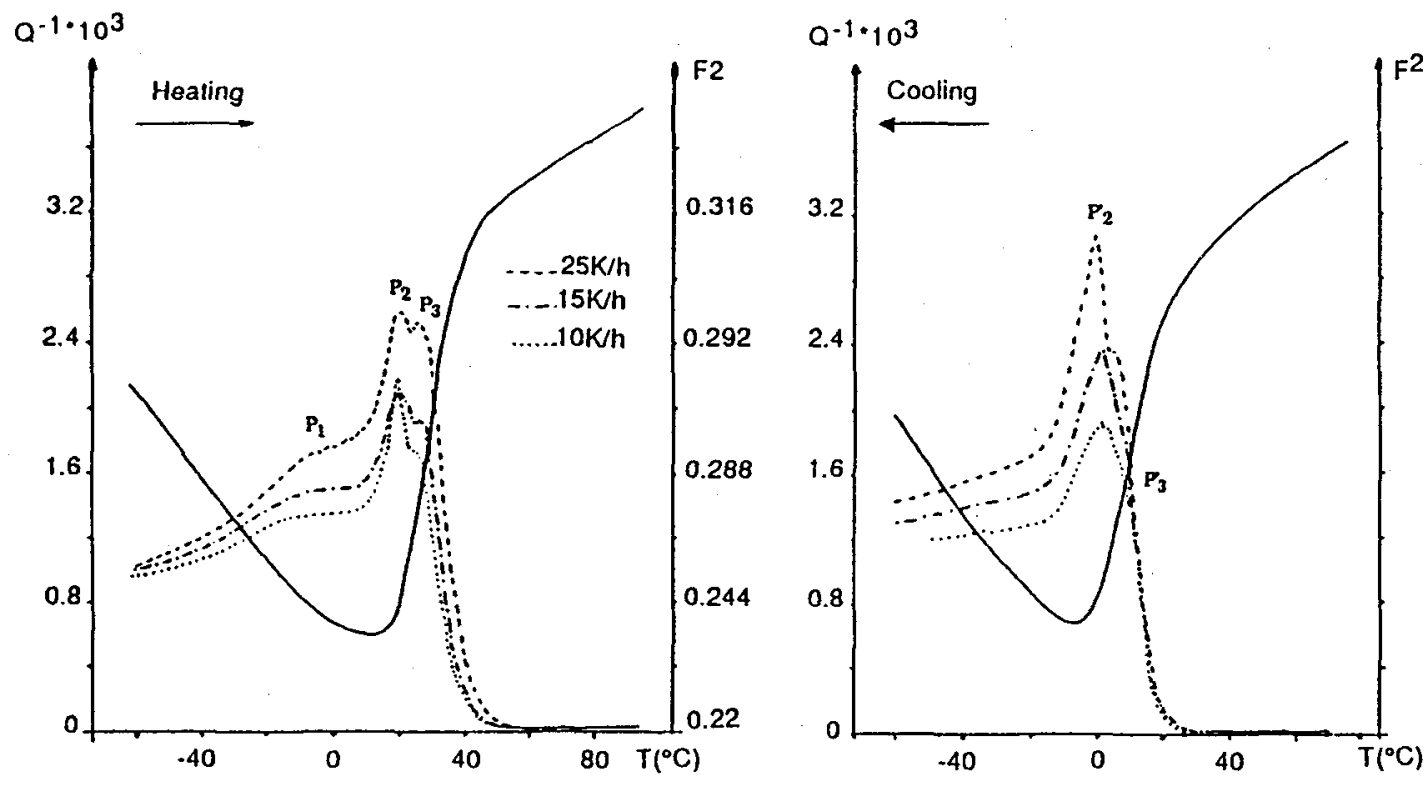

Fig. 2 : Internal friction spectra of $\mathrm{NiTiCu}$ alloys.

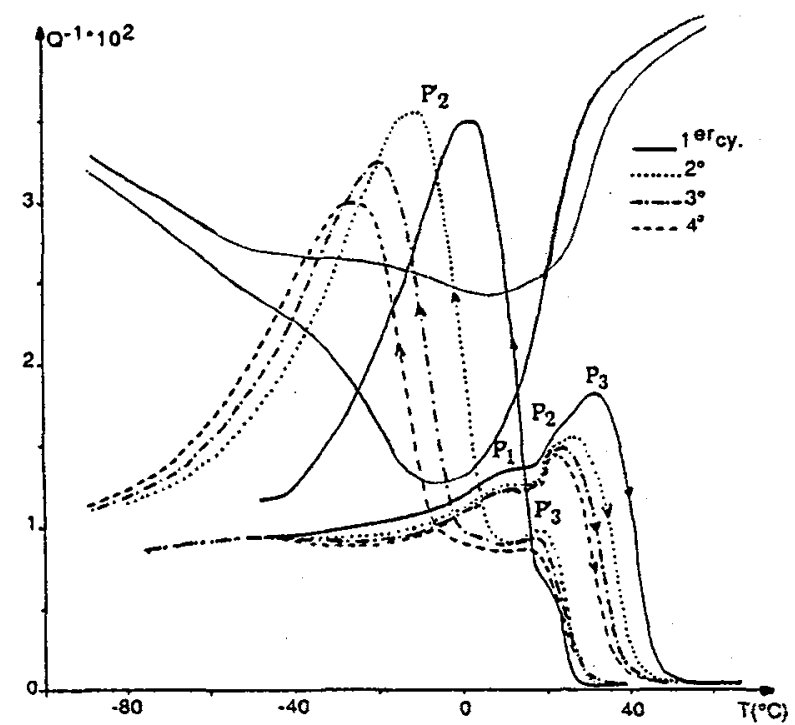

Fig. 3 : Internal friction spectra of NiTiCo alloys.

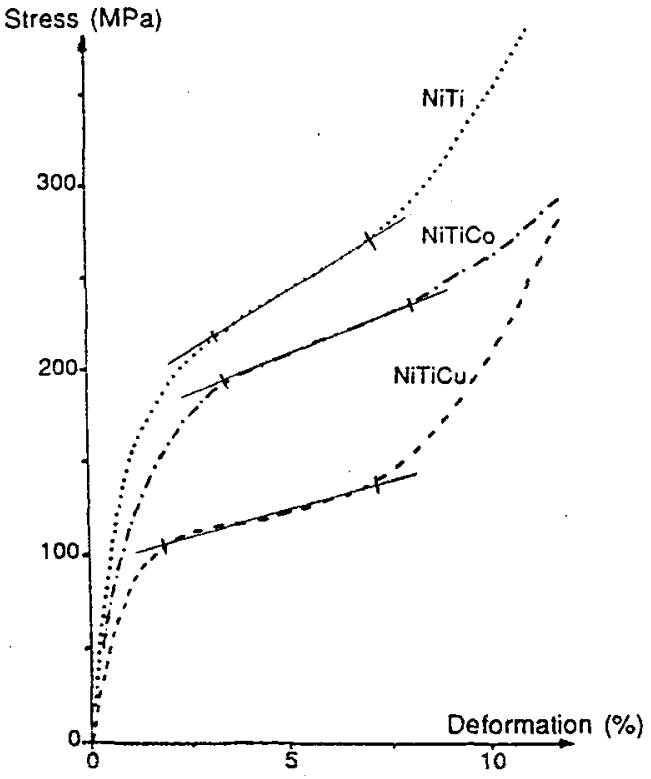

Fig. 4 : Deformation of alloys as a function of stress. 


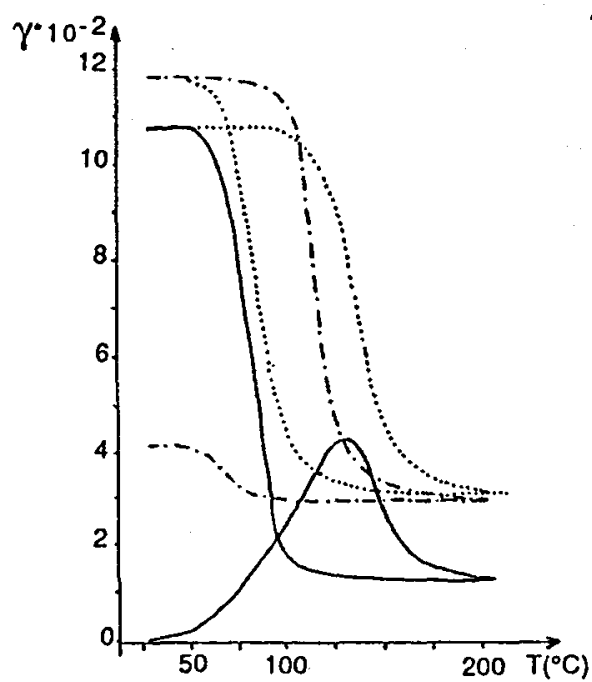

a) $\mathrm{NiTi} \quad \tau=200 \mathrm{MPa}$

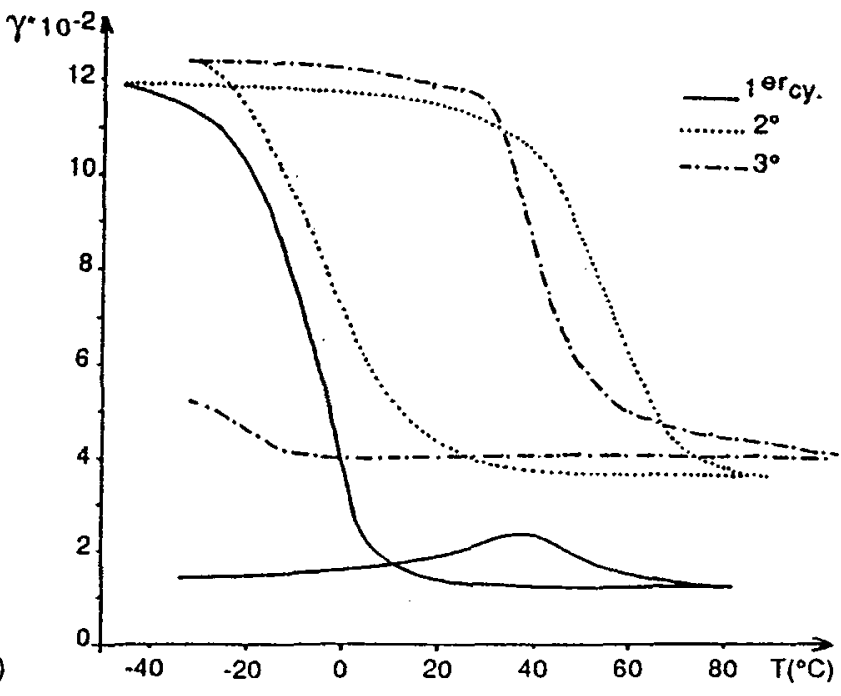

b) NiTiCo $\tau=140 \mathrm{MPa}$

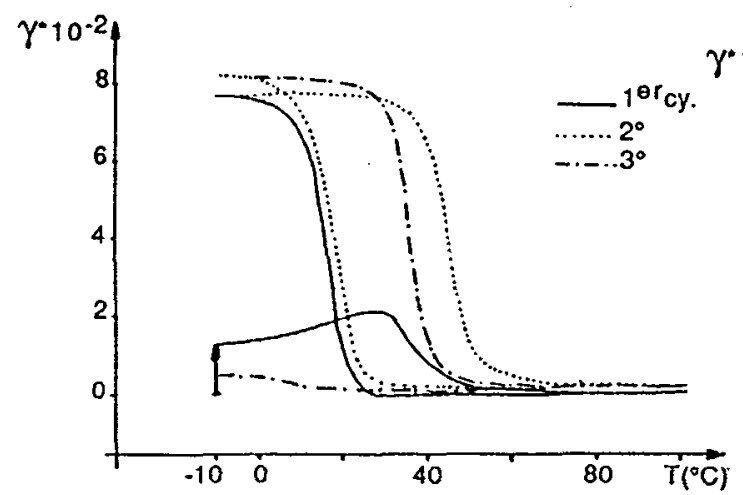

c) $\mathrm{NiTiCu} \tau=84 \mathrm{MPa}$

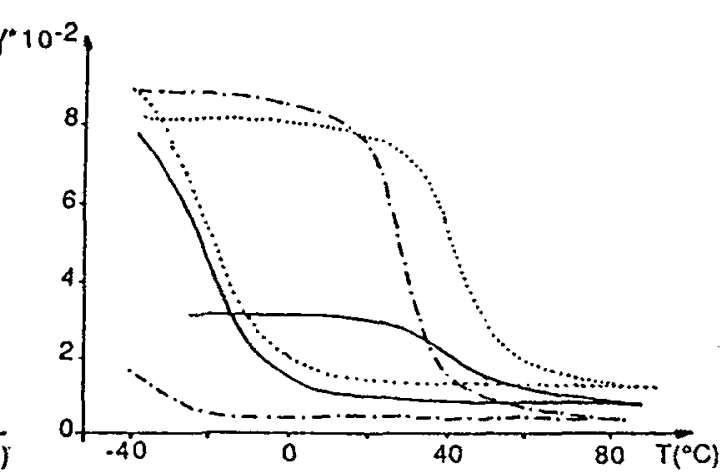

d) NiTiCo $\tau=70 \mathrm{MPa}$

Fig. 5 : Deformation of alloys as a function of temperature, $\gamma=f(T), \tau=$ constant. 